\title{
Van dorpsbewoner tot wereldburger
}

AUTEUR Karen Stuyck

FOTOGRAFIE Karen Stuyck en Wim De Maeyer

Integratie van migranten in de gastmaatschappij en aanhoudende verbondenheid met de maatschappij van herkomst zijn niet noodzakelijk elkaars tegengestelden. Aan de hand van de werking van enkele Senegalese migrantenorganisaties wordt duidelijk dat beide aspecten probleemloos gecombineerd kunnen worden en dat de potenties van zulke transnationale organisaties te vaak onbenut blijven.

De traditionele focus van migratiestudies is eenzijdig, vaak gelimiteerd tot de impact van migranten op de ontvangende maatschappij. Transnationale migratie en mondialisering hebben de relatie tussen migranten en hun gemeenschappen van herkomst in sterke mate gewijzigd. Technische innovaties zoals de gsm, fax, satelliettelevisie, het internet en goedkopere transportmogelijkheden maken het mogelijk om meer en betere banden te onderhouden met de familie of gemeenschap van oorsprong. Dit heeft het leven van migranten complexer gemaakt en steeds meer migranten zijn simultaan geëngageerd in hun thuisland en in het land van aankomst. Integratie in de ontvangende maatschappij en plichten verbonden aan de maatschappij van herkomst vervangen elkaar niet noodzakelijk, maar kunnen complementair zijn. Deze bijdrage wil dieper ingaan op bepaalde migrantenverenigingen die integratie in de gastmaatschappij en verbondenheid met de maatschappij van herkomst combineren. Hierbij wordt gebruik gemaakt van gesprekken met vertegenwoordigers van Senegalese verenigingen in België (8), sleutelpersonen van dorpsverenigingen in Senegal (5), Senegalese migranten in België (50), en dorpsbewoners in Senegal (20).

De verenigingen tonen aan dat integratie en transnationale verbondenheid niet tegengesteld hoeven te zijn. De projecten die zij ondersteunen zijn zeer verscheiden en afhankelijk van de ruimte (gastland of land van herkomst) waarin zij plaatsvinden. In het gastland kan dit bijvoorbeeld gaan om juridische of medische bijstand, terwijl in de gemeen- schap van herkomst projecten ondersteund worden die betrekking hebben op het verbeteren van publieke voorzieningen zoals het bouwen van scholen. Dit type van transnationale verenigingen werkt op basis van sterke netwerken in het gastland en sterke banden met de regio van herkomst. Slechts een beperkt aantal bevolkingsgroepen kennen zulke hechte netwerken die resulteren in transnationale verenigingen. Deze bijdrage wil dieper ingaan op de werking van enkele Senegalese verenigingen in België die opgericht zijn als antwoord op de noden van migranten in het gastland en de noden van hun dorpsbewoners aan de Senegalrivier. Naar het voorbeeld van enkele succesvolle migrantenorganisaties in Frankrijk proberen Senegalese migranten zich eveneens in België te organiseren, vaak in kleine informele groeperingen. Zij zetelen voornamelijk in Antwerpen en Brussel, de belangrijkste verblijfplaatsen voor Senegalese migranten, maar kunnen eveneens leden hebben in andere delen van het land of zelfs in andere landen. Verbondenheid met een bepaalde plaats vormt het belangrijkste criterium voor lidmaatschap.

\section{Netwerkmigratie naar België}

In tegenstelling tot Frankrijk, Italië of Spanje is de Senegalese gemeenschap in België eerder beperkt, namelijk 1178 officieel ingeschreven Senegalezen in 2008. Het officieuze aantal is echter hoger aangezien er geen rekening gehouden wordt met mensen zonder papieren en Senegalezen die de Belgische nationaliteit hebben. De meerderheid van deze migranten is pas na 1990 in België aangekomen, ondanks de sluiting van de grenzen voor economische migratie. Netwerkmigratie vormt hiervoor de belangrijkste reden. In de eerste plaats kwam er een stijging van het aantal familieherenigingen aangevraagd door reeds gevestigde migranten. Daarnaast ontdekten studenten meer en meer de mogelijkheden van het voornamelijk Franstalige onderwijsaanbod. Zij probeerden - vaak zonder beurs - een studentenvisum te bemachtigen om zo naar België te migreren. Een derde groep migranten bereikte België via het religieuze Mouridennetwerk. Deze specifiek 


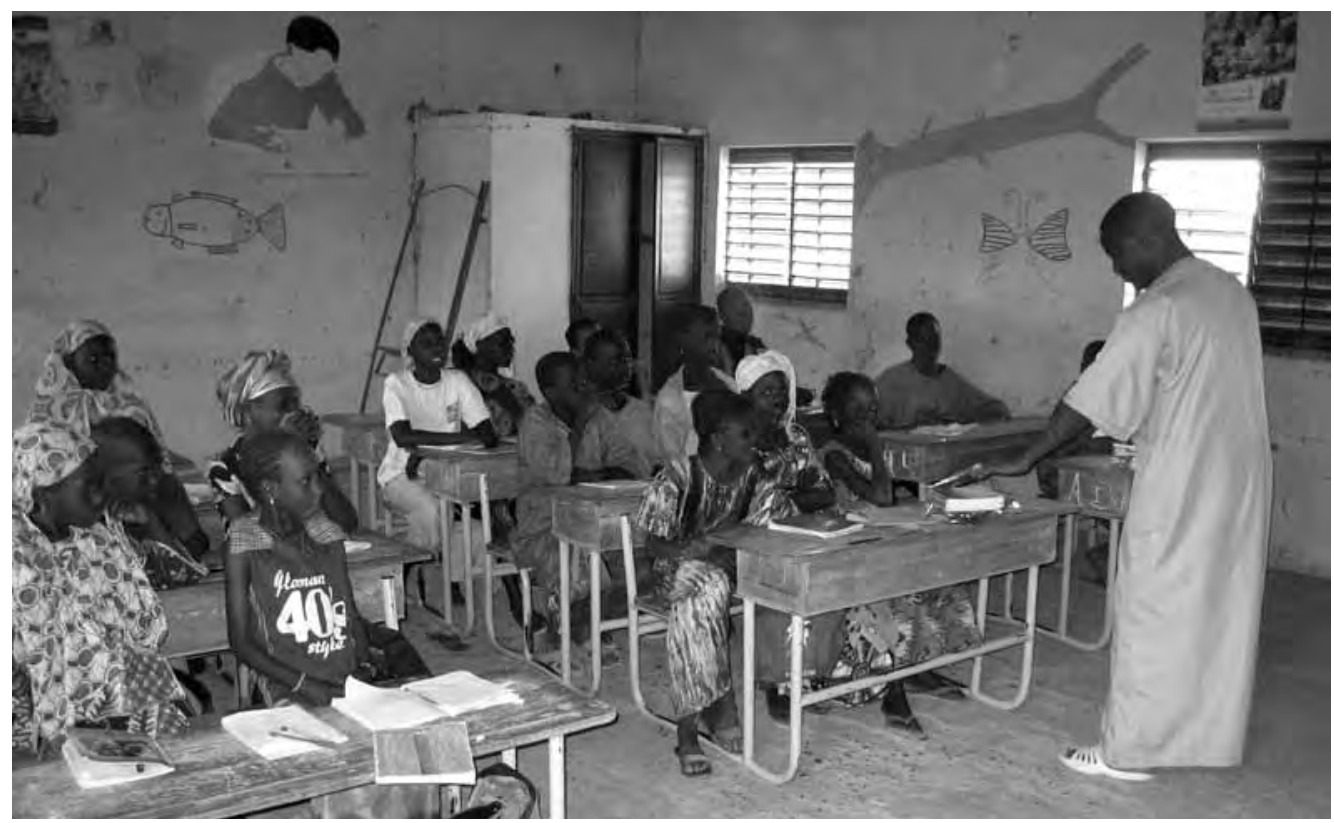

Door de bouw van verschillende klaslokalen wordt er nu basisonderwijs voorzien voor de jongeren van het dorp en omliggende dorpen. (foto: Karen Stuyck)

Senegalese islambroederschap is gekend voor zijn uitgebreide netwerk en de sterke handelscapaciteiten van de leden. Ze bezitten verschillende huizen in belangrijke steden over de hele wereld die dienst doen als gebedshuis en opvangplaats voor nieuwe migranten. Een vierde groep migranten kan zijn migratiedroom waarmaken door middel van een toeristenvisum om directe familieleden te bezoeken. Transnationale netwerken blijken zodoende de keuze van België als gastland in sterke mate te beïnvloeden. Zowat alle respondenten gaven bijvoorbeeld aan dat ze in België aankwamen met minstens één adres of telefoonnummer bij de hand en dat ze voor korte of langere tijd konden verblijven bij een landgenoot.

\section{'De oprichting van zulke solidariteitskassen duidt op het essentiële belang van een alternatief vangnet.'}

Deze transnationale netwerken doen de risico's en kosten verbonden aan migratie dalen en vormen een belangrijke bron van informatie voor potentiële migranten. Migranten functioneren als bruggenhoofd en verminderen de materiële en psychologische moeilijkheden verbonden aan migratie. De gevestigde migrantengemeenschap biedt hulp aan de nieuwe migranten in het vinden van werk, een woonplaats of verblijfspapieren. Op informele wijze wordt de integratie van nieuwe migranten zo reeds bevorderd. Het is dan ook niet verwonderlijk dat men deze ondersteuning tracht te bestendigen in de oprichting van een aantal formele en informele groeperingen die migranten van eenzelfde dorp, eenzelfde regio, eenzelfde religie of zelfs meerdere West-Afrikaanse landen verenigen. In eerste instantie richtten zij zich dus op het verbeteren van de levensomstandigheden in het gastland, maar omwille van hun verbondenheid met het land van oorsprong verlangen zij meer en meer om het leven in de gemeenschap van herkomst te verbeteren. Organisaties die dit dubbele doel beogen zijn voornamelijk dorpsverenigingen waarvan de leden afkomstig zijn uit eenzelfde dorp aan de Senegalrivier, maar het kunnen eveneens verenigingen zijn die zich richten op heel Senegal of één bepaalde regio.

\section{(Dorps)verenigingen als sociaal vangnet}

De dorpsverenigingen van Senegalese migranten afkomstig uit de regio van de Senegalrivier - associations villageoises of hometown associations - ontstonden in Frankrijk, waar migranten zich reeds groepeerden in het begin van de jaren '70 zeventig. De zogenaamde "foyers", die huisvesting boden aan de migranten, vormden een ideale omgeving om het collectieve solidariteitsgevoel aan te wakkeren. Hoewel het grootste deel Senegalese migranten momenteel uit Dakar afkomstig is, ligt de bakermat van de Senegalese migratie aan de Senegalrivier, waar de meeste dorpsverenigingen uit voortkomen. Migratie vanuit de vallei van de Senegalrivier is enerzijds een antwoord op de aanhoudende droogte en anderzijds een antwoord op de monetaire noden die steeds groter worden in deze economisch gemarginaliseerde zone. Jongeren worden weggestuurd om elders de nodige middelen te zoeken in naburige steden, in Dakar, Frankrijk of elders. Zo leven deze bevolkingsgroepen reeds dertig jaar in een 'meervoudige ruimte' waarbij het dorp zich ontdubbelt en waarbij er verenigingen opgericht worden op alle plaatsen waar er zich migranten bevinden. Dit kan in de hoofdstad Dakar zijn, maar eveneens in andere Afrikaanse landen waar er Senegalese migranten wonen (zoals Gabon, Ivoorkust, Mali,...) of Europese of Westerse bestemmingslanden (bijvoorbeeld Frankrijk, België, Italië, Spanje, Canada,...). Noch afstand, noch het verschil in levenswijze heeft de band met het geboortedorp verzwakt.

Ook in België bevinden zich enkele van deze dorpsverenigingen, ontstaan door de aanwezigheid van afkomstnetwerken. Dat er meerdere migranten uit hetzelfde dorp in België wonen is geen toeval. Transnationale netwerken en netwerkmigratie vormen de belangrijkste 


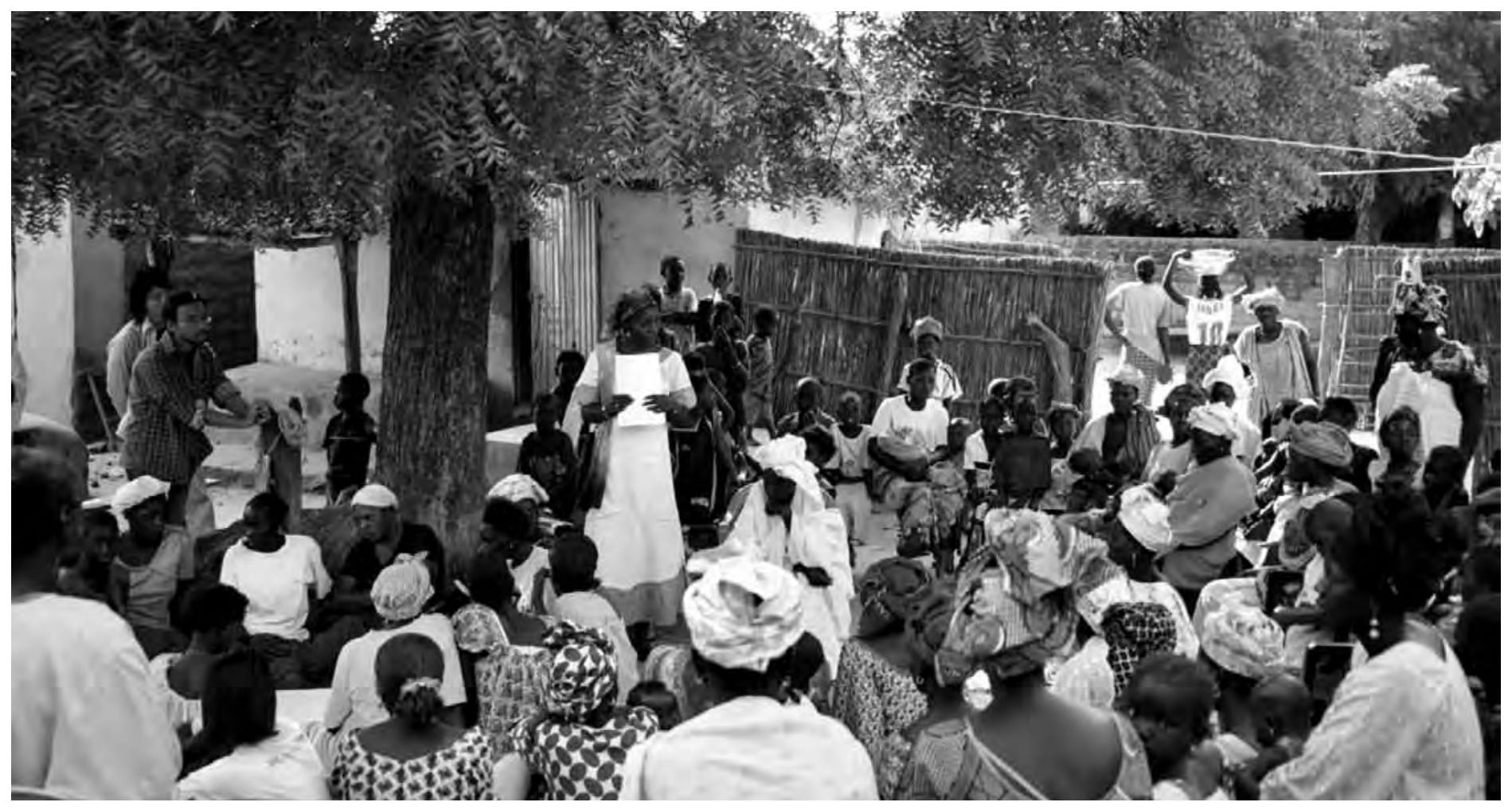

Vergadering met de vrouwen van een dorp over hun specifieke noden (foto: Wim De Maeyer)

redenen voor een vestiging in België. Deze persoon geeft bijvoorbeeld aan dat hij meerdere personen afkomstig uit zijn dorp in eerste instantie heeft opgevangen:

'Ik ben als eerste in België aangekomen met een beurs. Daarna heb ik altijd goed werk gehad en een huis kunnen kopen. De meerderheid van de aanwezige migranten uit mijn dorp heeft België gekozen omwille van mijn aanwezigheid. ledereen die hier aankwam en niet wist waarheen heeft hier een tijdje verbleven, soms zelfs twee jaar. Wanneer ze werk vonden of hun papieren kregen, moesten ze vertrekken'

- Man, 55 jaar, Brussel, afkomstig uit de regio van de Senegalrivier.

Deze groeperingen zijn in België omwille van het beperkte aantal leden zeer informeel, maar werken wel met een zekere efficiëntie. Ze vergaderen op welbepaalde tijdstippen, stellen een penningmeester en voorzitter aan, verzamelen elke maand de collectieve bijdragen van de leden (bijvoorbeeld 5 of 10 euro per maand) en houden de noden in het gastland en in het land van herkomst nauwgezet bij. Omwille van de informele status van de meeste organisaties, zijn ze onzichtbaar in de stad. Ze hebben geen specifiek kantoor, maar vergaderen waar er plaats is, eventueel bij iemand thuis. De oprichting van een VZW komt er soms pas na vele jaren wanneer enkele van de leden zich de Belgische wetgeving eigen gemaakt hebben, eventueel met hulp van Belgische vrienden.

In de eerste plaats vormen deze verenigingen een belangrijk vangnet voor sociale problemen in België. Zij functioneren als een vorm van mutuele verzekering waar men beroep op kan doen bij specifieke problemen. De zekerheid dat in geval van overlijden het lichaam gerepatrieerd wordt naar Senegal en daar begraven wordt, vormt één van de belangrijkste activiteiten. Ook andere sociale problemen - bijvoorbeeld wanneer iemand ernstig ziek is of juridische bijstand nodig heeft of zelfs in geval van problemen met de scholing van de kinderen - kan beroep gedaan worden op de kas van de vereniging. Dit vangnet is er gekomen voor zij die buiten het sociale zekerheidssysteem vallen of zij die slachtoffer zijn van grote tegenslagen.

In Senegal vormt de familie de belangrijkste sociale zekerheid, in België de staat. Een groot deel Senegalezen zijn in België zonder familie of zonder papieren, waardoor ze tussen de mazen van beide netten vallen. De solidariteitskas van de dorpsvereniging neemt deze functie over en is essentieel voor het overleven van sommige migranten. De activiteiten die deze verenigingen ondersteunen, zijn afhankelijk van vereniging tot vereniging en van de mate van formalisering. Kleine informele dorpsverenigingen zijn flexibeler, terwijl grotere solidariteitskassen strikte regels hanteren (dit is bijvoorbeeld gebruikelijk in Frankrijk waar sommige dorpsverenigingen tot 600 leden tellen). Wanneer de kas van de vereniging een bepaalde kost niet kan dekken, zal er beroep gedaan worden op de solidariteit van alle leden in de vorm van een bijkomende bijdrage (naast de maandelijkse bijdrage).

Geïnspireerd op de solidariteitskassen van zulke dorpsverenigingen en omwille van de nood aan een sociaal opvangnet zijn er omwille van de kleine gemeenschap in België eveneens solidariteitskassen ontstaan die los stonden van één bepaald dorp en zich eerder richten op dezelfde etnische groep of zelfs de hele Senegalese (of zelfs West-Afrikaanse) gemeenschap. Zij verschijnen voornamelijk in de twee belangrijkste steden voor Senegalese migranten, Antwerpen en Brussel. Zij helpen eveneens in geval van repatriëring van het lichaam bij overlijden, bij achterstallige huur, juridische problemen, medische problemen of in geval van een plots vertrek naar Senegal om dwingende redenen. De oprichting van zulke kassen duidt op het essentiële belang van een 
alternatief vangnet. In samenspraak met de leden worden er bepaalde voorwaarden opgelegd om een goede gang van zaken te garanderen. Door het creëren van een eigen systeem van sociale zekerheid slagen mensen zonder papieren, of migranten die tijdelijk in moeilijkheden leven er toch in om te overleven. Sociaal kapitaal wordt omgezet in economisch kapitaal, wat essentieel is om te overleven. Ruimtelijke nabijheid vormt zelfs geen voorwaarde om zich aan te sluiten en deel te nemen. Belgische solidariteitskassen hebben bijvoorbeeld ook leden in andere landen van Europa:

'We hebben ook leden in Frankrijk en in Italië. Zij hebben wel soortgelijke verenigingen in hun land, maar deze zijn vaak verbonden aan een specifiek dorp. Gezien de kleine gemeenschap in België richten wij ons op iedereen en die migranten uit Frankrijk en Italië hebben zich, na een vakantie bij familie of vrienden in België, dan bij ons aangesloten. Tegenwoordig kan dat allemaal goed geregeld worden en bestaan er geen grenzen meer voor solidariteit'

- Voorzitter solidariteitskas Antwerpen, afkomstig uit de regio van de Senegalrivier.

Hoewel ruimtelijke nabijheid en het beleven van de (alledaagse) problemen van de Senegalese migranten in Brussel of Antwerpen wel belangrijk was voor de oprichting van de verenigingen, is - eens bestendigd - ruimtelijke nabijheid niet essentieel meer voor solidariteit. Het zich verbonden voelen door dezelfde afkomst en vertrouwen hebben in een bepaalde vereniging op basis van transnationale netwerken vormen de belangrijkste ingrediënten voor de goede werking. De sociaal-economische organisatie van Senegalezen komt op die manier tot uiting op specifieke plaatsen in de Westerse wereld, maar door toenemende mondialisering (betere communicatie- en transportmogelijkheden) kan dergelijke organisatie eveneens van op afstand doorleven.

\section{'Migranten en dorpsbe- woners ontpoppen zich als belangrijke ontwikkelings- actoren'}

\section{Dorpsverenigingen als ontwikkelingshulp}

Het tweede doel van de (dorps)verenigingen is om hulp te bieden aan de gemeenschap van oorsprong. Dorpsverenigingen vormen het meest werkbare kader voor zulke activiteiten aangezien de noden van één bepaald dorp zeer concreet in kaart gebracht kunnen worden. Andere migrantenverenigingen die zich organiseren rond een bepaalde regio of religie hebben eveneens het voornemen om het land van oorsprong vooruit te helpen, maar slagen hier vaak niet in omwille van organisatorische problemen, enerzijds om voldoende subsidies bij elkaar te krijgen en anderzijds om duidelijke projecten af te bakenen in het land van herkomst. Migranten die behoren tot een welbepaalde dorpsvereniging slagen vaak wel door elke maand (of op een afgesproken tijdstip) geld bij elkaar te brengen om zo bij te dragen aan collectieve belangen van het dorp. De meest courante investeringen omvatten het voorzien in basisinfrastructuur; het aanleggen van elektriciteit of zorgen voor drinkbaar water; en het voorzien van infrastructuur voor publieke diensten zoals scholen, ziekenhuizen, moskeeën of marktplaatsen. De meeste dorpsverenigingen hebben zusterverenigingen in andere steden in de wereld en met het dorp van oorsprong. Wanneer je slechts met enkele leden van een dorp in een bepaald land woont, kan je je eveneens aansluiten bij de vereniging van het dorp in een ander (naburig) land. De verschillende verenigingen staan met elkaar in contact en wisselen informatie uit over de noden in het dorp en mogelijke oplossingen.

'Het dorp meldt ons bijvoorbeeld dat ze een probleem hebben met de watertoren en dan bekijken wij hoe we dat kunnen financieren. Maar elke vereniging in elk land betaalt een klein deel. Frankrijk draagt bijvoorbeeld meer bij dan Ivoorkust en Ivoorkust draagt meer bij dan de vereniging in Dakar. Ook het dorp draagt bij, maar meestal door het inzetten van hun arbeid, want wat zij verdienen is praktisch nul'

- Man, 45 jaar, Brussel, afkomstig uit de regio aan de Senegalrivier.

Elke migrant of dorpsbewoner draagt zo in de mate van het mogelijke bij aan de ontwikkeling van zijn dorp, migranten over de hele wereld door middel van economisch kapitaal, de dorpsbewoners zelf vaak door middel van hun arbeid. Een dorpsvereniging in België heeft bijvoorbeeld de lokale basisschool uitgebreid van één enkele klas naar negen klassen en kan nu basisonderwijs aanbieden voor het hele dorp en omliggende dorpen. Op deze wijze dienen zij impliciet de tweede doelstelling van de millenniumdoelen (recht op basisonderwijs voor alle kinderen). Deze millenniumdoelstellingen zijn opgemaakt in 2000 en zijn een akkoord tussen de verschillende landen van de Verenigde Naties om tegen 2015 de belangrijkste wereldproblemen aan te pakken. Zulke dorpsverenigingen maken dus een wezenlijk verschil voor de gemeenschappen van oorsprong. Migratie maakt dat zowel de 'achtergebleven' dorpsbewoners als de migranten plots deel uitmaken van een transnationale wereld waarbij informatie, geld en goederen over de grenzen heen uitgewisseld worden, niet enkel bilateraal tussen België en Senegal, maar zelfs multilateraal met migranten die zich gevestigd hebben in andere delen van de wereld. Het dorp staat zo in verbinding met de hele wereld, en ondanks het verlies aan arbeidskrachten in het dorp danken zij een deel van hun ontwikkeling aan deze transnationale connectie. Door middel van sterke netwerken slagen deze migranten erin om het eigen leven in het gastland en het leven van de dorpsbewoners in de gemeenschap van herkomst te verbeteren.

\section{Besluit}

Bovenstaande voorbeelden tonen aan dat migrantennetwerken cruciaal zijn voor het overleven van de Senegalese migranten in België, maar ook voor de gemeenschap van herkomst. Enerzijds zorgen migrantennetwerken voor een ruimtelijke structurering van de migranten in welbepaalde steden over de hele wereld, maar anderzijds zijn ruimte en nabijheid relatieve begrippen geworden. Men staat in contact met 


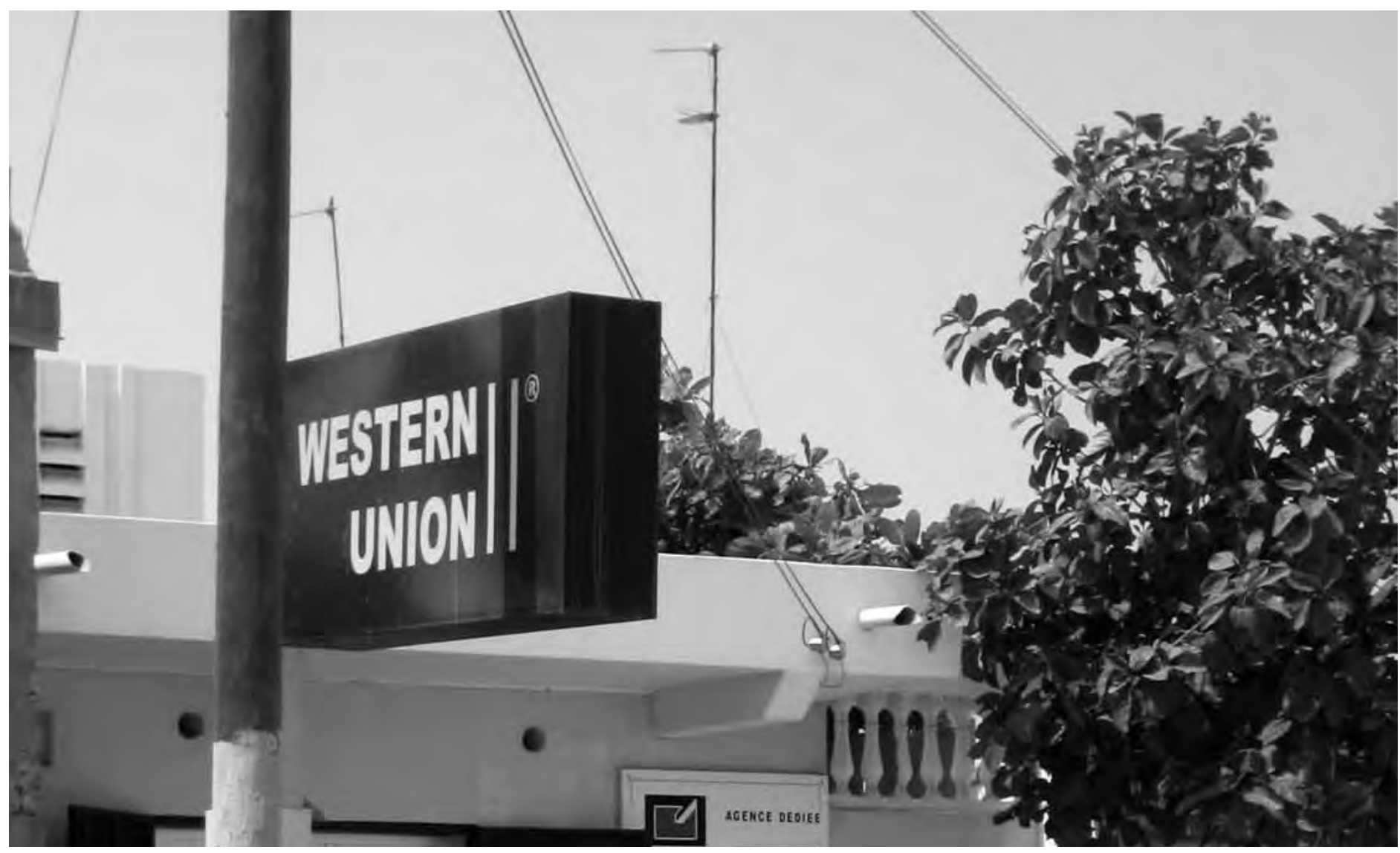

Kantoren van geldtransfersbedrijven worden veelvuldig gebruikt en maken deel uit van het straatbeeld in zowel de Westerse maatschappij als de maatschappij van herkomst (foto: Karen Stuyck)

dorpsgenoten over de hele wereld en bij afwezigheid van een belangrijk netwerk in het migratieland, kan men zich aansluiten bij de vereniging in een ander land. Sociaal kapitaal zorgt ervoor dat economische kapitaal herverdeeld of gedeeld wordt met enerzijds migranten in moeilijkheden in het migratieland en anderzijds met het dorp. Nochtans is de uitwisseling van deze kennis tussen de migranten en de dorpsbewoners niet altijd evident. Noch de dorpsbewoners, noch de migranten zijn immers opgeleid als ontwikkelingshelpers, maar door hun transnationale manier van leven en zich organiseren ontpoppen zij zich als belangrijke ontwikkelingsactoren en helpen bewust of onbewust de millenniumdoelstellingen te verwezenlijken.

Net op dat vlak zijn er in België en Nederland nog heel wat gemiste kansen. Migranten beschikken over de nodige kennis van het terrein, de nodige contacten, maar ontbreken vaak financiën en de essentiële kennis om projecten te doen slagen. NGO's en andere ontwikkelingsactoren beschikken over de middelen en de nodige competenties om een project succesvol op te starten en te begeleiden. Het lijkt voor de hand te liggen dat deze verschillende actoren elkaar vinden, maar dat gebeurt niet of te weinig omwille van bureaucratische en andere problemen. In andere Europese landen zijn nochtans voorbeelden te vinden van goede samenwerking tussen herkomstlanden en migrantenorganisaties. Frankrijk heeft bijvoorbeeld met Senegal en Mali co-developement programma's waar ontwikkelingsorganisaties en migrantenorganisaties samenwerken. Over zulke samenwerkingen kunnen Belgische en Nederlandse organisaties voorlopig alleen maar dromen.
Karen Stuyck (karen.stuyck@ees.kuleuven.be) is doctoraatstudente verbonden aan het Instituut voor Sociale en Economische Geografie van de KU Leuven.

\section{Literatuurselectie}

Basch, L., Glick Schiller, N. \& C. Blanc-Szanton (1994) Nations Unbound. Langhome: Gordon and Breach.

De Haas, H. (2007) Migration and Development: a Theoretical Perspective. COMCAD Working Papers.

Depuy, C. (1990) Les associations villageoises au Sénégal: fonctions économiques et modalités de financement. Technologie et développement 31, nr. 122, pp.351-375

Dieng, S.A. (2002) Pratiques et logiques de l'épargne collective chez les migrants maliens et sénégalais en France. Afrique et développement 27, nr. 1 \& 2, pp. 144-174

Faist, T. (2008) Migrants as transnational development agents: an inquiry into the newest round of the migration-development nexus. Population, space and place 14 , pp. $21-42$

Goldring, L. (2003) Re-thinking Remittances: Social and Political Dimensions of Individual and Collective Remittances. CERLAC Working Papers Series. 